\title{
Cómo la covid-19 ha cercenado el envejecimiento activo y la calidad de vida de las nuevas generaciones
}

\author{
How covid-19 has limited active ageing and lowered \\ the quality of life of younger generations
}

M. Carrión Fernández-Pacheco

\section{Resumen}

La covid-19 ha repercutido en el bienestar de todas las personas, y no solo en el ámbito de la salud: también en el social, el económico, el afectivo, el psicológico... Además, no ha afectado a todas por igual. Distintos factores han provocado una incidencia mayor en distintos colectivos, siendo el más castigado el de las personas mayores. Pero si a la cuestión de la edad se le suman otras variables, como la discapacidad, la soledad, la falta de recursos..., las consecuencias pueden ser devastadoras. Por ello, es importante poner el foco en colectivos concretos para conocer aquellos aspectos que les han afectado durante esta pandemia, tanto los compartidos con el conjunto de la población como aquellos que les han influido específicamente. En las siguientes líneas se hace un breve análisis de lo que esta crisis sanitaria ha supuesto y está suponiendo para el colectivo concreto de las personas mayores con discapacidad visual, desde cómo se ha visto afectada la dignidad de estas hasta el impacto en su día a día, sin dejar de mencionar los apoyos y movimientos solidarios que se han movilizado para atender las necesidades del colectivo y una reflexión sobre un futuro en el que se tendrán que aplicar las lecciones aprendidas durante esta crisis.

\section{Palabras clave}

Personas mayores. Covid-19. Discapacidad visual. Derechos y libertades. 


\begin{abstract}
Covid-19 has impacted everyone's welfare, and not only in terms of physical health, but also socially, economically, affectively and psychologically. Nor has everyone been affected equally. Due to a number of factors, the effects have been felt more severely by some communities, the elderly especially. But where age is exacerbated by other variables such as disability, solitude or limited resources... the consequences can be devastating. Hence the importance of focusing on specific communities to ascertain the matters of greatest concern to them during the pandemic, both those shared with the population as a whole and those impacting them specifically. The present article briefly analyses what this health crisis has meant and continues to mean for the community of elderly people with visual disability, ranging from its implications for their dignity to its impact on their daily lives. The solidary action instituted to attend to their needs is also discussed, along with considerations around the application in future situations of the lessons learnt in this crisis.
\end{abstract}

\title{
Key words
}

Elderly people. Covid-19. Visual impairment. Rights and freedoms.

\section{Introducción: las personas mayores en la primera línea}

EI SARS-CoV-2, covid-19 o coronavirus -tal y como se denomina coloquialmente-, que se inició, parece ser, de forma fortuita en tierras muy lejanas de oriente, a finales del año 2019, está suponiendo el reto sanitario más importante para la humanidad del siglo XXI y, posiblemente, marcará en muchos aspectos la vida futura.

En el caso de las personas mayores, únicamente los más longevos recuerdan vagamente lo que les contaban sus padres sobre la pandemia generada por la denominada «gripe española», que diezmó la humanidad a finales de la Primera Guerra Mundial y cuyo origen, según parece, estuvo muy lejos de nuestro país.

Epidemias locales, por desgracia, ha habido muchas, y alguna de ellas se ha atrevido a saltar fronteras, pero el alcance de la actual crisis sanitaria está siendo claramente global y planetaria.

Una regla que se cumple indefectiblemente es que cuando hay crisis, conflictos, guerras o epidemias, quienes pagan el precio más caro son los más débiles, los que

Carrión, M. (2021). Cómo la covid-19 ha cercenado el envejecimiento activo y la calidad de vida de las nuevas generaciones. RED Visual: Revista Especializada en Discapacidad Visual, 77, 43-52. https://doi.org/10.53094/ WRQE5999. 
tienen menos medios y, en el caso de la covid-19, especialmente las personas mayores o aquellas que han tenido alguna patología previa, conjuntamente con las personas socialmente excluidas.

A diferencia de lo que sucedió con la mencionada «gripe española», que atacó prioritariamente a personas jóvenes y adultas, dejando a las mayores de lado, la actual pandemia se ha cebado de una forma importante en el colectivo de gente mayor.

Sin duda ninguna, en la actual pandemia, el elemento que ha contribuido más a su rápida transmisión y a su esparcimiento por todo el planeta es la globalización, la posibilidad de poder viajar de un extremo al otro del mundo en pocas horas, facilitando que también viajen con las personas los virus y, por lo tanto, el problema se globalice.

Asimismo, la globalización y la especialización, en diversas zonas del mundo, en la fabricación de productos necesarios, por motivos económicos y en muchos casos con prácticas de explotación de los trabajadores, ha provocado la escasez de material sanitario y de primera necesidad.

Por otra parte, la inexperiencia de los gobernantes, la timidez con la que, en determinados momentos, se han tomado medidas, los condicionamientos económicos, su falta de valentía, la inexistencia de coordinación de los recursos disponibles y las estrategias políticas han llevado consigo que las consecuencias de la infección hayan sido mucho peores en todo el mundo de lo que hubieran sido si se hubieran tomado las decisiones a tiempo y de una forma adecuada.

En este marco general y global y, dado que el virus ha tenido una gran penetración infecciosa en las personas de más edad, el colectivo de personas mayores está sufriendo de forma muy intensa las consecuencias sanitarias de la pandemia.

Además, a todo esto, hay que sumar que a las personas mayores que no pueden vivir solas, la sociedad las ha recluido en residencias, creadas en muchas ocasiones por grandes compañías que quieren tener el máximo beneficio, a veces con pocos escrúpulos, jugando con sus vidas.

Se le puede dar muchas vueltas, explicarlo de muchas formas y usar muchos artilugios literarios, pero la consecuencia final para muchas de las personas de más edad ha sido la enfermedad y la muerte. 


\section{El olvido al respeto a la dignidad de las personas mayores}

Lo que ha sucedido en gran parte del mundo con el colectivo de las personas mayores el año 2020 hubiera podido formar parte perfectamente de un guion de una novela de terror, $y$, de hecho, lo ha supuesto para millones de personas y sus familias que lo han vivido en primera persona.

No solo ha afectado la especial virulencia de la enfermedad, acrecentada con la edad de las personas, sino que hay una serie de efectos que, de forma paralela, han puesto en evidencia -incluso en los países más desarrollados y que disfrutan del estado de bienestar- las carencias de los sistemas asistenciales y de protección, la falta de tino de los políticos, los intereses económicos de las empresas farmacéuticas y una nueva guerra para repartirse el mundo entre las grandes potencias.

Millones de personas de Europa de 65, 70, 80 y 90 años, solo por mencionar unas edades, o han fallecido, o han enfermado, o han sido recluidas, muchas veces en condiciones inhumanas impropias de sociedades avanzadas.

Permanecen en las mentes las situaciones de algunas de las residencias de personas mayores y de la priorización no confesada, atendiendo a motivos de edad en la atención a enfermos en las unidades de cuidados intensivos, sobre todo, a finales de marzo y durante el mes de abril del año pasado que tuvieron una incidencia brutal sobre el colectivo sénior.

Se recuerda, claramente, a esas personas que sufrieron y murieron sin poder despedirse de sus seres queridos, cuando la pandemia sacudió por sorpresa a la humanidad, sorpresa que la cogió con el pie cambiado por no haber sido previsores a tiempo.

Por otra parte, se sufre la soledad y el aislamiento al que estamos sometidos las personas mayores, tanto en los propios domicilios como en las residencias, durante ya casi un año y medio de unas vidas que, por ley natural, tienen un menor futuro.

Es por este motivo, por el hecho de disponer de menor perspectiva de vida, por lo que el tiempo invertido en salvar de la pandemia a las personas sénior supone un coste importantísimo en su trayectoria vital. 
Se ha visto que también en el primer mundo: los países se han apropiado de parte de los derechos de las personas mayores al tomar decisiones por ellas, sin pedírsele opinión. Se ha limitado el horario de salidas a pasear, se ha obligado a permanecer en casa sin salir ni tan solo a la calle, provocando todo ello deterioro físico, psicológico y relacional.

Como a muchos ciudadanos, a las personas mayores les ha asaltado la preocupación por los familiares a quienes se ayudaba: hijos, nietos, tareas escolares, actividades extraescolares, etc., sentir inquietud por los familiares en paro, en ERTE, y preocupación por la evolución de las empresas.

\section{Mucho más difícil para las personas ciegas o con discapacidad visual}

Y todo esto y mucho más, en lo que se podría extender muchísimo, se ha visto todavía acrecentado para las personas mayores con alguna discapacidad y, más concretamente, con ceguera o grave discapacidad visual.

Para las personas ciegas tiene una especial relevancia el trato en la corta distancia, y el uso del tacto y el olfato, conjuntamente con la audición, son el radar de posicionamiento y relación con el medio y la sociedad, canales que se han visto limitados desde marzo del año pasado.

Como para el resto de la sociedad, se ven restringidas las actividades en grupo, las convivencias, las actividades sociales, situación que, sumada a la falta de visión, está golpeando duramente a este colectivo.

Las personas ciegas en residencias, en ocasiones, han sufrido el aislamiento suplementario que conlleva el no ver, el ir con miedo de tocar cosas o personas y la falta de percepción del entorno.

Hace pocos días, hablando telefónicamente con diversas personas afiliadas que han estado en residencias, explicaban que, en algunos casos, estuvieron encerrados 15 días en su habitación porque había infecciones en su residencia, o que, aún hoy, estando ya vacunados, no pueden salir a pasear por la calle $o$ ir a visitar a sus se- 
res queridos. Lo realmente indignante es que, para muchas personas mayores, esta reclusión forzosa, lejos de servir para luchar contra la pandemia, les ha supuesto la enfermedad y la muerte.

Las personas ciegas que viven solas están también sufriendo mucho esta nueva lacra de la sociedad, llamada «soledad no deseada», agravada por la limitación que supone la falta de visión para establecer nuevas relaciones sociales, todo ello en el marco de las medidas de distanciamiento.

Durante los meses de confinamiento, los perros guía han perdido el hábito de guiar a sus usuarios, al no poder ejercitar su función durante meses, ya que la movilidad se vio restringida al entorno domiciliario, entrenamiento que se tendrá que ir recuperando poco a poco dentro de lo posible.

Después de una vida de trabajo, se ha soñado con la jubilación para viajar, participar en vacaciones sociales, turnos del Imserso de turismo y termalismo, y esta crisis sanitaria, lejos de relajar y dejar disfrutar a las personas mayores de los años que les quedan de vida, han traído ansiedad, soledad y aislamiento.

Y si a la falta de visión se le suma la de la audición, tal y como sucede con las personas con sordoceguera, para las que el contacto directo es su único medio de comunicación con el mundo, el aislamiento, la angustia y el miedo se ven trágicamente multiplicados.

La reclusión domiciliaria ha hecho perder autonomía en exteriores, traído recelo a que los otros evitasen el acercamiento y la proximidad, para las personas ciegas tan necesaria.

Las comunicaciones electrónicas han sustituido, en muchos casos, las presenciales y el contacto personal y, nuevamente en este caso, muchas personas ciegas han sufrido las consecuencias de la brecha digital; en definitiva, de no poder acceder a lo que accede el resto de la población por el hecho de estar privados del sentido de la vista.

Además, las Administraciones han creado herramientas tecnológicas para realizar consultas sobre la pandemia, comunicar positivos, realizar el seguimiento y ser llamados a vacunación, $y$, en muchos casos, estas herramientas no han sido creadas para que puedan ser usadas por personas ciegas o con grave discapacidad visual, con lo que se ha sufrido una nueva discriminación. 
Y nuevamente, ahora con las vacunas, convocan mediante un mensaje de texto en el móvil, cuando muchas personas ciegas mayores no disponen de este recurso tecnológico o no saben usarlo. Además, convocan en grandes instalaciones, desconocidas, sin dar el más mínimo apoyo para la movilidad, creándose verdaderas dificultades.

Se hace un pequeño paréntesis para hablar de las vacunas, que aun afirmando rotundamente que es un gran logro de la humanidad por la rapidez en su diseño, la forma en que se está comunicando todo lo que a los procesos de vacunación se refiere, a las características de las diferentes vacunas o a las contraindicaciones, parece que está pensado para confundir y generar ansiedad en la población, sin hablar del juego geopolítico que, a nivel mundial, se está viviendo con un tema tan importante.

Y, por si fuera poco, con un alarde de falsa transparencia, políticos, tertulianos y medios de comunicación bombardean durante 24 horas al día con noticias, indicaciones, contraindicaciones, cambios de criterio inexplicables y verdades a medias, que no hacen más que acrecentar la angustia.

Los párrafos anteriores no pretenden ser enunciativos ni descriptivos, ni profundizar en todos y cada uno de los aspectos mencionados y los muchos que no se tratan por no alargarlo en demasía, son únicamente ejemplos de cómo la ceguera o la baja visión, sumadas a la edad, hacen que esta crisis sanitaria suponga dificultades suplementarias.

Sin desear que se convierta en pesadillas, se anima al lector del artículo a que haga un breve ejercicio para imaginarse como estaría pasando la pandemia desde su inicio siendo una persona mayor $y$, además, padeciendo ceguera; cómo pasaría el tiempo, cómo iría a comprar, cómo andaría por la calle y cómo lo tendría que tocar todo para saber qué hay frente a él.

\section{La solidaridad y el voluntariado unidos ante la adversidad}

Los movimientos solidarios en general y los de voluntariado han tenido un auge importante, y supieron llegar donde los poderes públicos no tenían capacidad organizativa o económica o, sencillamente, no atinaron en pensar que existía una necesidad. 
La ONCE, su Red de Referentes del Mayor, ${ }^{1}$ SUPO, ${ }^{2}$ etc., desde el primer minuto de la pandemia y del confinamiento inicial, pusieron en marcha medidas para mitigar, dentro de lo posible, los efectos especialmente negativos que la crisis podía tener en las personas ciegas.

Se han realizado grandes campañas para mantener contacto con los afiliados, en especial con las personas mayores y aquellos que viven solos, para ofrecerles apoyo y ayudarles en su día a día.

De inmediato, se potenciaron iniciativas para facilitar a aquellos que lo precisaban el acceso a temas, tan básicos, como la compra de víveres y productos de primera necesidad, realizando, en pocos días, decenas de miles de llamadas telefónicas para detectar las necesidades prioritarias de las personas ciegas o con baja visión.

Se han organizado actividades no presenciales, potenciando el uso de las nuevas tecnologías, dirigidas a aquellas personas que lo deseaban y tienen capacidad para ello.

Se han fomentado las charlas, actividades lúdicas, el ejercicio físico; en definitiva, se ha utilizado la imaginación para conseguir hacer de forma no presencial lo que antes se hacía con el contacto directo.

Una especial dedicación ha supuesto el trabajar con los afiliados que lo precisaban para mantener su tono emocional en un correcto balance, con el apoyo psicológico justo, para afrontar esta situación en la que se carece de experiencia.

La ONCE ha seguido prestando sus servicios, multiplicando, si cabe, las atenciones para ayudar a los afiliados que lo necesitaban, y las personas mayores han reinventado su forma de hacer cosas, estando desde la distancia cerca de la gente.

Y, desgraciadamente para todos, esto todavía no se ha acabado. Tanto desde el voluntariado por parte de los que ya no trabajan, como desde la profesionalidad de los que están en activo, se sigue ayudando a aquellos que les rodean y que lo necesitan, en especial si son ciegos.

1 Canal de comunicación, integrado por personas afiliadas mayores, para la proximidad permanente a todos los afiliados mayores de la ONCE.

2 Colectivo Sénior de Unidad Progresista de la ONCE, estructurado y organizado. 


\section{Una lección para el aprendizaje por un futuro mejor}

No se puede forzar hasta el límite a la naturaleza porque es obligado vivir en el planeta azul, para la actual generación y las que vendrán en el futuro.

Muchos científicos lo advertían en los últimos años $y$, de hecho, se han tenido grandes sobresaltos en el siglo XXI con la transmisión de epidemias y el surgimiento de nuevas enfermedades que, con la globalización, se pueden volver con facilidad de ámbito planetario.

De hecho, estos científicos están convencidos de que esta no va a ser la única pandemia que la humanidad padecerá en este siglo, y que, cada vez, las epidemias provocadas por virus o bacterias desconocidos hasta el momento serán más frecuentes si no se toman medidas.

Por lo tanto, es necesario que la humanidad en general y cada uno dentro de sus posibilidades cambien muchos hábitos, muchas de sus conductas, se respete más al medio natural, se sea menos avariciosos y se cuide un poco más el futuro, no tanto el porvenir de las personas mayores - que, por ley de vida, habitarán menos años en el planeta- como el de las personas jóvenes, que tienen sus vidas y las de sus descendientes por delante.

Habrá, también, que aprender a elegir a los dirigentes, depositando en sus manos la confianza, con el encargo claro de cambiar el mundo, para hacerlo más humano y respetuoso con el planeta Tierra.

Esta lección que se está viviendo ha de devolver la modestia, la humildad y concienciar a los habitantes del mundo de ser unos meros inquilinos y no propietarios de la Tierra. Es un bien precioso a disfrutar como usufructuarios, que hay que dejar en las mejores condiciones para los que vengan detrás.

Al mismo tiempo, se ha evidenciado que nadie es indestructible, que cada persona forma parte de un sistema complejo, que, de un día para el otro, puede sufrir un desequilibrio y poner en grave riesgo a la especie humana.

También el mundo tiene que aprender a cuidar más a sus mayores, a aquellos que han posibilitado que la humanidad tenga un desarrollo, que se han dejado las vidas para 
que sus descendientes puedan vivir mejor que ellos y a los que no se puede pagar todo ese esfuerzo dejándoles aparcados en un rincón, esperando el fin de sus días.

La responsabilidad no es únicamente de los gobernantes, de los que llevan las riendas de las grandes corporaciones, sino que cada uno, dentro de sus vidas diarias, pueden tomar muchas decisiones que conduzcan al mundo hacia los cambios imprescindibles para que lo que es de todos, lo de vivir en la Tierra, dure muchos siglos más.

Los ciegos sénior también han aprendido muchas cosas con la pandemia, pero, sobre todo, a ser más solidarios y mejores con los que nos rodean, práctica que se recomienda al lector que ejercite, aunque solo sea por el egoísmo personal de sentirse bien.

Manuela Carrión Fernández-Pacheco. Referente Estatal del Mayor. Consejo General de la ONCE. Ortega y Gasset, 18; 28006 Madrid (España). Correo electrónico: mancf@once.es. 